\begin{tabular}{ccc}
\hline & International Journal of Engineering \& Technology, $7(2.19)(2018) 41-44$ \\
SPC & Website: $w w w . s c i e n c e p u b c o . c o m / i n d e x . p h p / I J E T$ & Technology \\
\hline
\end{tabular}

\title{
Analysis of modern construction projects using montecarlo simulation technique
}

\author{
A. M. Arunmohan ${ }^{1 *}$, Dr. M. Lakshmi ${ }^{2}$ \\ ${ }^{1}$ Department of Civil Engineering,Himalayan University,Arunachal Pradesh, India. \\ ${ }^{2}$ Department of Civil Engineering, Government Polytechnic College,Madurai, Tamil Nadu, India \\ *Corresponding author E-mail: arun.mohanb4u@gmail.com
}

\begin{abstract}
Today, Construction based Industry is the prospering industry which has a high economical influence on any nation. Delay in the huge construction project increases the total project cost. Henceforth, uncertainties as well as risks must be significantly regarded during the project. For organizing and completing the projects in a financially, timely and qualitatively accountable manner, careful scheduling of projects is compulsory. Effectual scheduling of project assures project success. This study concentrates on qualitative analysis, risk identification, together with quantitative analysis. The targets are i) to ascertain the key risk aspects that disturb the project schedule, and ii) to find the probability of finishing the project within specified time. Questionnaires are distributed amongst 20 industry practitioners with disparate experience from [1] to [25] years. Quantitative analysis is made by the methods like Monte Carlo simulation (MCS) and PERT. @ RISK by Palisade corp. is utilized for MCS.
\end{abstract}

Keywords: Monte Carlo Simulation; PERT; Qualitative and Quantitative Analysis; Risk Identification

\section{Introduction}

Construction projects probably complete within a specified period. Delay in any project augments the entire cost of a project and the contractor also faces the penalty for causing such delay. Henceforth it is significant for the contractor and the owner to follow the schedule which is allotted for the respective project.

Scheduling is considered as the significant measure of construction project management. Planning, in addition, scheduling of construction works aids engineers to end the project within the budget and time. However, construction works possess risks /uncertainties that may delay the performance of some activities or even augment the project cost. Henceforth, it is significant to introduce a process of risk management. This process handles the risks that disturb the execution of project schedule.

In construction schedule, this study of risk management intended to find the key factors that delay the completion of a specific activity. The risk may arise again and it may cause problems in the completion of a proposed project. Therefore, this study proffers a solution for those risk factors. A risk is recognized as an uncertain condition or event that when arises affects one or more targets of the project like time, scope, objective, cost, etc. A risk may have one or more causes and if it occurs it may have one or more impacts. The parameters that associated with risk are,

- Extension of the project.

- Higher costs.

- Failure to attain the specified information requirements.

- Failure to accomplish the specified quality requirements.

- Failure to accomplish the stated organizational requirements.

Usual 6 categories of risks in the construction area are,

- Scheduling risk

- Legal risk
- $\quad$ Financial risk

- Technical risk

- Management risk

- Environment risk

\section{Literature review}

Chaudhari and Ganame [1] identified the key risk factors that disturb the project success by utilizing Pert and MCS, @RISK by palisade corp. The hostel construction project was examined and finished within a specified period.

Nemuth [2] considered and evaluated the process of risk management in the German construction based industry by the utilization of a risk analysis tool. For the construction project evaluation in the tender phase centered on MCS, this process places the management in a better position as it understands and assesses the project in addition to its risks precisely. Moreover, it is probable to filter higher risk projects in an initial stage and to monitor those projects separately.

Guadalupe and Valderrama [3] considered the contrast of tenders for the implementation of works tendered within procurement systems centered on i) open to re-measurement and ii) unit contract prices which needs analysis tools. This tool is ought to be capable of discriminating betwixt proposals having a similar overall amount which may signify diverse final economic impact. Spanish companies and construction professionals have less knowledge about MCS method. This method is easy to apply and it has adequate tools. However, it was centered on assumptions. The required data is readily identified by those who wish to utilize it.

Peleskei et.al [4] describes the difficult arena of determining and quantifying the risks and also their impacts on project costs in the 
construction industry. It was found that historical data utilized for an MCS gives project manager an idea of the variation in costs.

Rajgor [5] studied the factors that cause delay and evaluated the critical factors causing delay, and finally identified the key factors and diminish the effect of the delay by utilizing RII technique.

\section{Analysis}

Relative Importance Index (RII)

It is utilized to find the relative importance of the several causes together with the effects of delays. The method is implemented within numerous groups (e.g. project engineers, contractors, site supervisor and owner). The four-point scale ranging from 1 (lesser degree affect) to 4 (higher degree affect) is adopted and transmuted to RII for every factor as follows:

$$
\mathrm{RII}=\Sigma \mathrm{W} /(\mathrm{A} * \mathbf{N})
$$

Where, $\mathrm{A}$ is the maximal weight (i.e. 4). $\mathrm{N}$ is the total number of respondents. $\mathrm{W}$ is the weight provided to every factor by the respondents (range 1-4). Highest the RII value, more vital is the cause of delays.

Table 1: RII with Rank

\begin{tabular}{lll}
\hline Factors & RII & Rank \\
\hline DDF (Design and Documentation Related Factors) & 0.813 & 2 \\
FIN (Financial Management Related Factors) & 0.658 & 7 \\
ICT (Communication Related Factors) & 0.686 & 6 \\
MMF (Material And Machinery Related Factors) & 0.708 & 5 \\
Human Resource Related Factor(LAB) & 0.718 & 4 \\
PMCA (Project Management Related Factors) & 0.789 & 3 \\
CSM (Contractors Site Management Related Factors) & 0.928 & 1 \\
External Factors (EF) & 0.627 & 8 \\
\hline
\end{tabular}

Table 2: From the Above Ranking Using RII, the First Five Factors Causing Cost Overrun Was Listed Below

\begin{tabular}{lll}
\hline Factors & RII & Rank \\
\hline $\begin{array}{l}\text { CSM (Contractors Site Management } \\
\text { Related Factors) }\end{array}$ & 0.928 & 1 \\
$\begin{array}{l}\text { DDF (Design and Documentation } \\
\begin{array}{l}\text { Related Factors) } \\
\text { PMCA (Project Management }\end{array}\end{array}$ & 0.813 & 2 \\
$\begin{array}{l}\text { Related Factors) } \\
\text { Human Resource Related }\end{array}$ & 0.789 & 3 \\
$\begin{array}{l}\text { Factor(LAB) } \\
\begin{array}{l}\text { MMF (Material And Machinery } \\
\text { Related Factors) }\end{array}\end{array}$ & 0.718 & 4 \\
\hline
\end{tabular}

\section{Drawings}

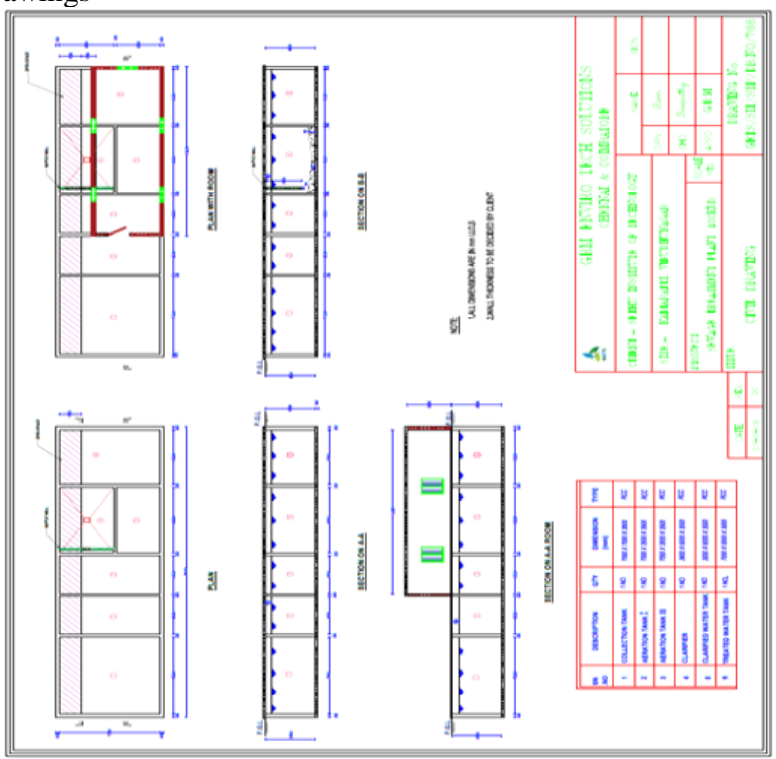

Fig. 1: Sewage Treatment Plant Drawing.

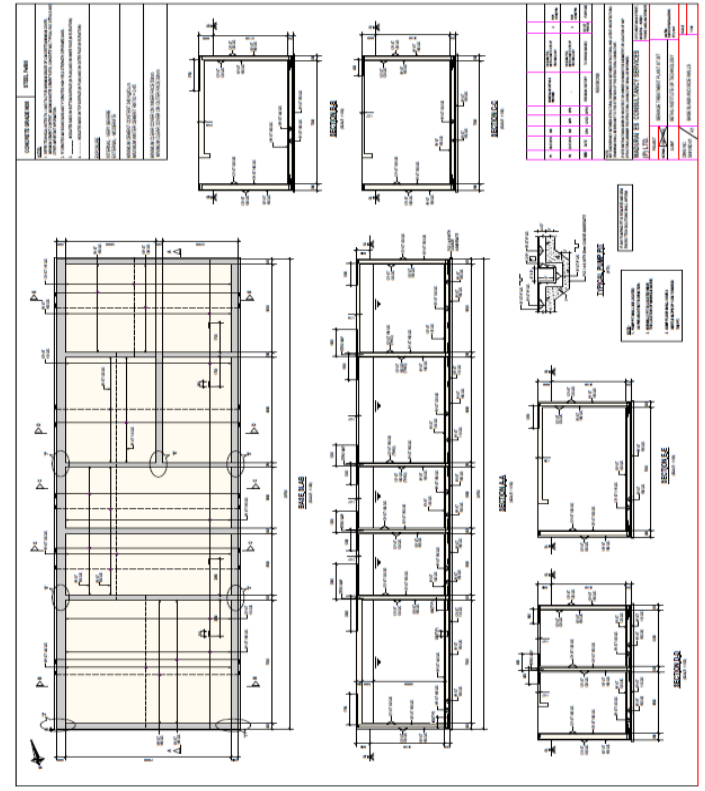

Fig. 2: Base Slab and Side Walls Structural Drawing.

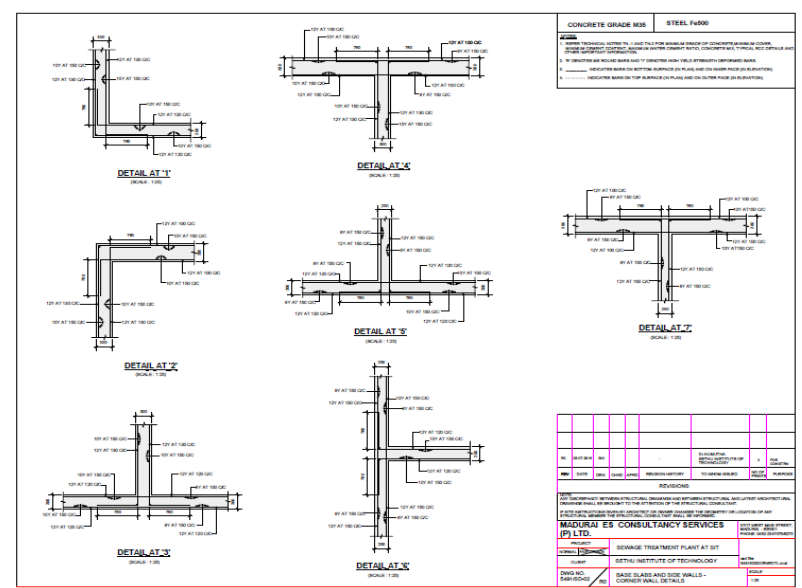

Fig. 3: Base Slab and Side Walls - Corner Wall Details Structural Drawing.

\section{Monte carlo simulation technique}

MCS/probability simulation is a technique utilized to recognize the influence of risk/uncertainty in project management, forecasting models, and financial cost.

Once a forecasting model (i.e. a model that plans ahead for the upcoming future) is developed, some assumptions are made. They are about i) the cost of a construction project, ii) the investment return on a portfolio, or iii) how long it will take to finish a certain task because those are the projections to the future. Therefore, with those assumptions estimate the probable value.

The real value can't be determined but centered on expertise in the field, or historical data, or past experience, certain estimates are made. Whilst this estimate utilized for developing a model, it contains certain inherent risk and uncertainty, because it is an estimate of an unknown value.

In some situations, it is probable to estimate some ranging of values. In a construction project, it is probable to estimate the time taken to complete a particular job; centered on some expert knowledge. In the worst possible case, the estimation of the absolute maximal time is possible, and in the best possible case, the estimation of the absolute minimal time is possible. The same steps are followed for estimating project costs. In a financial market, the estimation is centered on the distribution of probable values through the standard deviation and mean of returns. 
By utilizing a possible range of values, as a substitute for one guess, generate a more accurate picture of what might occur in the upcoming future. When a model is centered on ranging of estimates, the final output of that model will also be in a ranging.

This is dissimilar from a usual forecasting model, in which it starts with certainly fixed estimates - say the time it will take to finish each 3 project parts - and end with other value - the aggregate time for the project. If the same model is centered on ranging of estimates for each 3 project parts, the outcome would be a ranging of times it might take for completing the project. When each part has a maximal and minimal estimate, by utilizing those values estimate the total maximal and minimal time of the project.

\section{Results \&discussion}

Qualitative analysis is utilized to prioritize the risks in accordance with their severity so that the risks are further subjected to this analysis. The succeeding table displays the outcome of the qualitative analysis. After computation of pessimistic and optimistic time, all the 3 durations are updated in the software. The succeeding table displays the computation of durations by MCS.

\begin{tabular}{lllll}
\multicolumn{5}{c}{ Table 3: Simulated Times } \\
\hline Activity & $\begin{array}{l}\text { Simu- } \\
\text { lated time }\end{array}$ & $\begin{array}{l}\text { Optimis- } \\
\text { tic time }\end{array}$ & $\begin{array}{l}\text { Most } \\
\text { likely } \\
\text { time }\end{array}$ & $\begin{array}{l}\text { Pessimis- } \\
\text { tic time }\end{array}$ \\
\hline $\begin{array}{l}\text { Sewage Treat- } \\
\text { ment Plant (STP) }\end{array}$ & 91.67 & 76 & 88 & 123 \\
$\begin{array}{l}\text { Below ground } \\
\text { level }\end{array}$ & 84.67 & 71 & 81 & 114 \\
$\begin{array}{l}\text { Earthwork Exca- } \\
\text { vation }\end{array}$ & 7 & 7 & 7 & 8 \\
$\begin{array}{l}\text { Plain cement con- } \\
\text { crete (PCC) }\end{array}$ & 6.83 & 5 & 6 & 12 \\
$\begin{array}{l}\text { Base slab con- } \\
\text { crete }\end{array}$ & 10 & 8 & 9 & 16 \\
$\begin{array}{l}\text { Wall } \\
\text { Cover slab }\end{array}$ & 36.5 & 27 & 35 & 52 \\
$\begin{array}{l}\text { Above Ground } \\
\text { Level }\end{array}$ & 25.17 & 27 & 28 & 35 \\
$\begin{array}{l}\text { Column } \\
\text { Pump room wall }\end{array}$ & 6.17 & 5 & 25 & 28 \\
\hline
\end{tabular}

Above table displays that the minimal completion time of the project is 76 days and maximal time is 123 days. After MCS, the completion time is 91.65 days on considering several identified risks. Descriptive graph and frequency statistics displays the mean completion time of the project is 92.65 days with 1000 trials. The maximal and minimal completion times are 93.670 days and 89.63 days respectively.

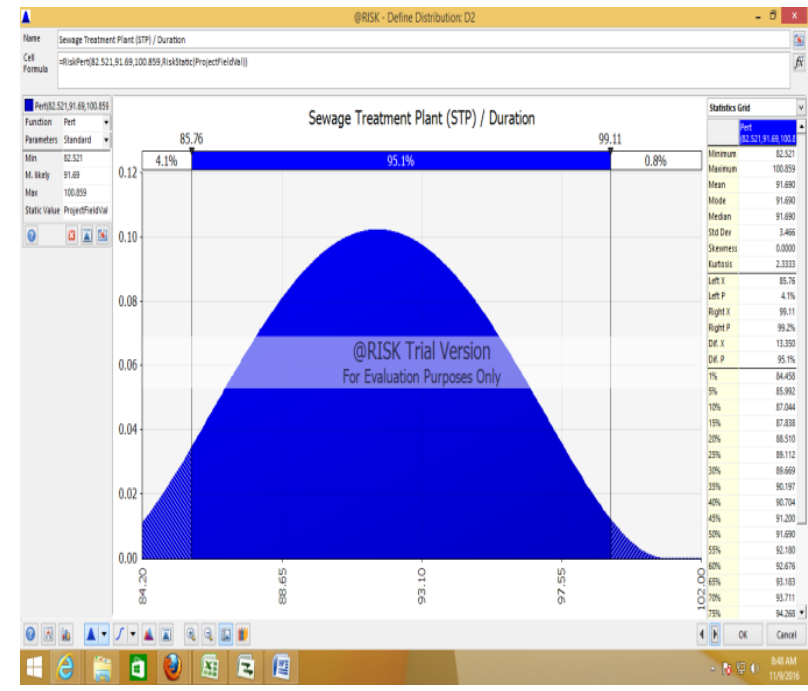

Fig. 4: Software Given the Pert Analysis Report.

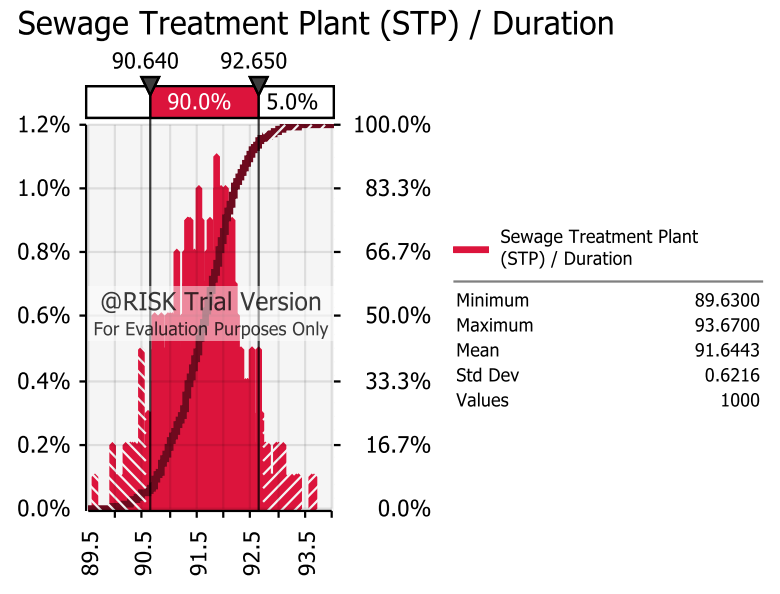

Fig. 5: Descriptive Graph and Frequency Statistics.

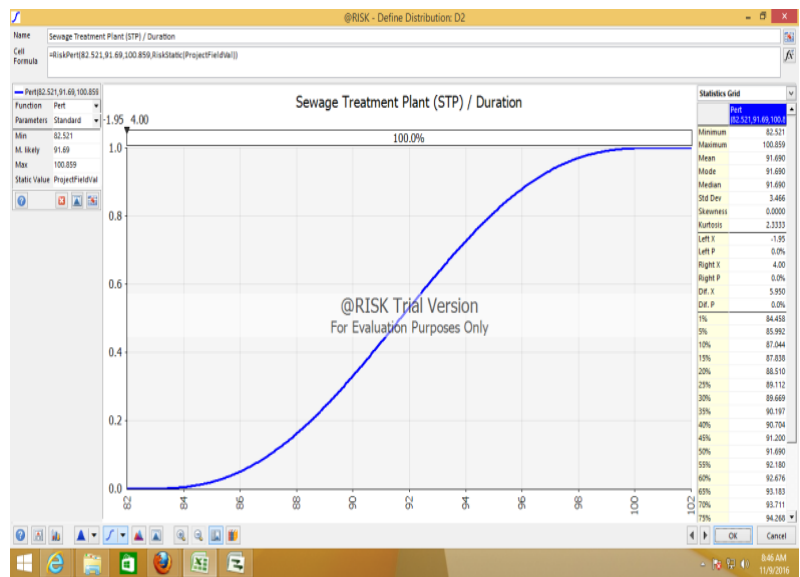

Fig. 6: Cumulative Frequency Graph

The percentage of project completion for several durations is displayed in table 4 . The outcomes obviously display that it is extremely unlikely to complete the project within 88 days $(0 \%)$. Also, there is $100 \%$ chance that the project gets completed in 92.65 days.

Table 4: Percentage of Completion Project

\begin{tabular}{|c|c|c|c|}
\hline \multicolumn{4}{|c|}{ Summary Statistics for Sewage Treatment Plant (STP) / Duration } \\
\hline Statistics & & Perce & \\
\hline Minimum & 89.63 days & $10 \%$ & 90.84 days \\
\hline Maximum & 93.67 days & $20 \%$ & 91.11 days \\
\hline Mean & 91.644 days & $30 \%$ & 91.33 days \\
\hline Std Dev & 0.6216 days & $40 \%$ & 91.5 days \\
\hline Variance & 0.386413952 & $50 \%$ & 91.66 days \\
\hline Left X & 90.64 days & $60 \%$ & 91.82 days \\
\hline Left P & $5 \%$ & $70 \%$ & 91.97 days \\
\hline Right X & 92.65 days & $80 \%$ & 92.15 days \\
\hline Right P & $95 \%$ & $85 \%$ & 92.25 days \\
\hline Diff X & 2.01 days & $90 \%$ & 92.44 days \\
\hline Diff P & $90 \%$ & $95 \%$ & 92.65 days \\
\hline
\end{tabular}

\section{Conclusion}

For the probability of completing the STP (Sewage Treatment Plant) within the specified time, the simulation utilizing @RISK software had exposed that the probability for the completion of project within 88 days is 0 (most likely duration). This exhibits that the due date centered on most likely durations which had been utilized by the construction based management team was not significant in an uncertainty environment; it is unlikely to be accomplished. The uncertainties direct the project management to risks and problems. The construction schedule should be revised recurrently, and the changes of due date may happen repeatedly. 


\section{References}

[1] Ganame P \& Chaudhari P "Construction building schedule risk analysis using Monte-Carlo simulation", International Research Journal of Engineering and Technologi, Vol. 2 (2015), pp. 1402-1406.

[2] Nemuth IT "Practical use of Monte Carlo simulation for risk management within the international construction industry", In Proceedings of the 6th International Probabilistic Workshop, Darmstadt. (2008).

[3] Valderrama FG \& Guadalupe R "Monte Carlo method applied to comparison of tenders in construction projects", 17th International Congress on Project Management and Engineering Logroño 17-19th (2013).

[4] Peleskei, CA Dorca V, Munteanu RA \& Munteanu R "Risk Consideration and Cost Estimation in Construction Projects Using Monte Carlo Simulation" Management knowledge and learning, Vol. 10, No. 2, (2015), pp. 163-176.

[5] Rajgor M, Paresh C, Dhruv P \& Chirag P, Dhrmesh B "RII \& IMPI: Effective Techniques For Finding Delay In Construction Project", International Research Journal of Engineering and Technology, Vol. 3, No. 1, (2016), pp. 1173-1177. 